\title{
Randomised trial of early diet in preterm babies and later intelligence quotient
}

\author{
A Lucas, R Morley, T J Cole
}

\begin{abstract}
Objectives To determine whether perinatal nutrition influences cognitive function at $71 / 2-8$ years in children born preterm.

Design Randomised, blinded nutritional intervention trial. Blinded follow up at 71/2-8 years.

Setting Intervention phase in two neonatal units; follow up in a clinic or school setting.

Subjects 424 preterm infants who weighed under $1850 \mathrm{~g}$ at birth; 360 of those who survived were tested at $71 / 2-8$ years.

Interventions Standard infant formula versus nutrient enriched preterm formula randomly assigned as sole diet (trial A) or supplements to maternal milk (trial B) fed for a mean of 1 month. Main outcome measures Intelligence quotient (IQ) at 71/2-8 years with abbreviated Weschler intelligence scale for children (revised).

Results There was a major sex difference in the impact of diet. At 71/2-8 years boys previously fed standard versus preterm formula as sole diet had a 12.2 point disadvantage (95\% confidence interval 3.7 to 20.6 ; $P<0.01$ ) in verbal IQ. In those with highest intakes of trial diets corresponding figures were 9.5 point disadvantage and 14.4 point disadvantage in overall IQ $(1.2$ to $17.7 ; \mathrm{P}<0.05)$ and verbal IQ $(5.7$ to 23.2; $\mathrm{P}<0.01)$. Consequently, more infants fed term formula had low verbal IQ (<85): $31 \%$ versus $14 \%$ for both sexes $(\mathrm{P}=0.02)$ and $47 \%$ versus $13 \%$ in boys $\mathrm{P}=0.009$ ). There was a higher incidence of cerebral palsy in those fed term formula; exclusion of such children did not alter the findings.

Conclusions Preterm infants are vulnerable to suboptimal early nutrition in terms of their cognitive performance - notably, language based skills-at $7 \frac{1}{2} 2-8$ years, when cognitive scores are highly predictive of adult ones. Our data on cerebral palsy generate a new hypothesis that suboptimal nutritional management during a critical or plastic early period of rapid brain growth could impair functional compensation in those sustaining an earlier brain insult. Cognitive function, notably in males, may be permanently impaired by suboptimal neonatal nutrition.
\end{abstract}

\section{Introduction}

Numerous studies have examined whether suboptimal nutrition in early life, at a critical or "vulnerable" phase of brain development, could affect later cognitive function $^{1-6}$-a matter of major public health and clinical concern. Most studies have been in developing countries, where malnutrition is so closely associated with poverty, poor social circumstances, and lack of stimulation that it has been difficult to extricate these influences from any potential long term effect of nutrition itself. ${ }^{67}$ While some recent evidence is compelling, ${ }^{38}$ firm conclusions are still hampered by the lack of large studies with adequate experimental design.
Clear demonstration of causal effects of early nutrition on long term neurodevelopment requires an experimental approach with strict randomisation of groups. Experimental studies in animals, mostly rodents, ${ }^{8-10}$ have shown that nutrition in early life can permanently affect brain structure and function, especially in males. Such studies in animals, however, have uncertain relevance for human cognitive development

In humans the so called "critical" spurt in brain growth is between the third trimester and 2 years postterm. ${ }^{5}$ We have designed a series of randomised prospective studies to test the vulnerability of the brain to suboptimal nutrition during specific periods of this growth spurt. Our most longstanding studies, started in 1982, were on preterm infants ${ }^{11}{ }^{12}$ and therefore designed to test effects of diet in the earliest period of the spurt in brain growth-before full term. In the early 1980 s diets available for preterm infants varied greatly in nutrient content, ${ }^{11}$ and it was ethical and feasible to assign these diets randomly as there was considerable uncertainty on optimal nutritional strategies. Our outcome studies have direct application for clinical practice ${ }^{13}$ and provide a unique opportunity to test formally the hypothesis that nutrition could influence long term cognitive performance.

In 1991 we reported the first of two parallel trials comparing effects of feeding infants born preterm a standard infant formula or a special preterm formula enriched with protein, energy, and micronutrients designed to meet the calculated nutritional needs of preterm infants. Despite the brevity of the early dietary manipulation-on average only the first postnatal month $^{12}$-we reported major reductions in motor and mental development indices at 18 months in the group fed on standard formula. Test scores at 18 months, however, are not strongly predictive of later cognitive development. ${ }^{14}$ We report here results of formal cognitive tests in these children at $71 / 2-8$ years, when any group differences in intelligence quotients would be likely to reflect permanent effects of early diet. ${ }^{15}$

\section{Methods}

We enrolled infants who weighed under $1850 \mathrm{~g}$ at birth and were admitted to the neonatal unit in Norwich throughout 1982-4 and in Sheffield during 1983-4. Ethical approval was obtained in each centre. Parental consent was always sought and was never refused. Only babies with major congenital malformations known to impair growth or development were ineligible.

\section{Randomisation}

Randomisation was as shown in figure 1. Infants of mothers who chose not to provide breast milk were randomly allocated to receive either a standard term formula (Ostermilk, previously Osterfeed, Farley Health Products) or a preterm formula designed (by us) to meet the calculated increased nutritional needs

\author{
Medical Research \\ Council Childhood \\ Nutrition Research \\ Centre, Institute of \\ Child Health, \\ London \\ WC1N 1EH \\ A Lucas, \\ MRC clinical research \\ professor \\ R Morley, \\ head of clinical trials \\ group \\ Medical Research \\ Council Dunn \\ Nutrition Unit, \\ Cambridge, \\ CB4 1XJ \\ T J Cole, \\ statistician \\ Correspondence to: \\ Professor Lucas
} A.Lucas@ich.ucl.ac.uk

BMJ 1998;317:1481-7 


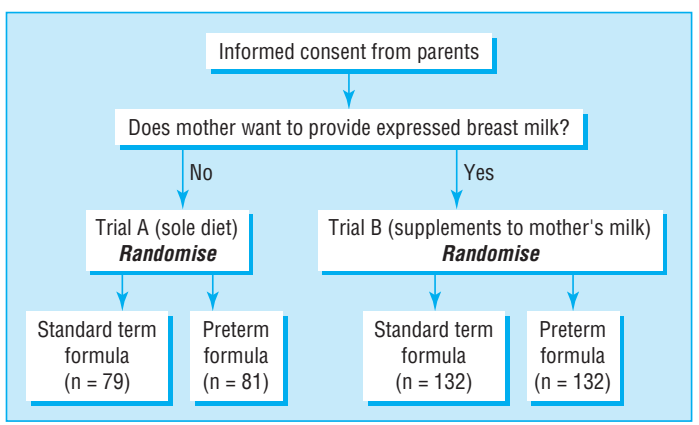

Fig 1 Design of longitudinal study of early diet and later developmental status. Comparison of standard term versus preterm formula for 424 infants weighing under $1850 \mathrm{~g}$ at birth

in preterm infants (Osterprem, Farley Health Products) as their sole diet (trial A). Those babies whose mothers chose to provide their breast milk were randomly allocated to receive the term or preterm formula as a supplement to breast milk (trial B). Intake of trial diet in trial $\mathrm{B}$ depended on the mother's success in providing her milk. The volume of formula and breast milk (if received) were recorded daily to allow the proportional consumption of these milks to be calculated over the study. Consumption of the trial diet varied from none to $100 \%$ intake (median 39\%; quartiles 5\% and $76 \%$ ) with no difference between babies supplemented with term (median 38\%) or preterm (41\%) formula.

It was planned that trials A and B would be treated independently and combined to compare babies randomly assigned a term formula (as sole diet or supplement) or preterm formula (as sole diet or supplement). Randomisation carried out in the first 48 hours after birth ${ }^{12}$ was by use of opaque sealed envelopes (numbered in consecutive order) and was conducted independently in each centre. Assignments were on the basis of permuted blocks of variable length. Within each trial randomisation was stratified by birth weight $(<1200 \mathrm{~g}$ and $1200 \mathrm{~g}$ or above) to increase the likelihood of equal distribution of sick babies between groups.

\section{Composition of formulas}

The formulas were identified by numeric code so that neonatal staff, parents, and eventually follow up staff were blinded to dietary assignment. The composition of the trial formulas is shown in table 1 . The quantity but not quality of protein and fat differed between the two formulas. The composition of expressed breast milk from daily analyses of samples from 24 hour milk collections was $1.5 \mathrm{~g}$ protein, $3.0 \mathrm{~g}$ fat, $7.0 \mathrm{~g}$ carbohydrate, $0.259 \mathrm{MJ}$ (62 kcal), $23 \mathrm{mg}$ sodium, $35 \mathrm{mg}$ calcium, and $15 \mathrm{mg}$ phosphorus per $100 \mathrm{ml}$.

After birth enteral feeds by nasogastric tube were increased according to tolerance; target intake was $180 \mathrm{ml} / \mathrm{kg}$ per day. In total 182 infants $(43 \%)$ required initial parenteral nutrition including amino acid infusion (with or without lipid). Median period to full enteral feeds was 9 (quartiles 7 and 14) days with no difference between groups. Trial diets were discontinued when body weight reached $2000 \mathrm{~g}$ or at hospital discharge, whichever was sooner. Because of prolonged growth failure 12 infants initially assigned standard formula (six in trial A) were changed to preterm formula for at least a week. Results from these children were analysed as randomised in accordance with the trial protocol (but excluded in a further analysis, see discussion).

\section{Data collected}

Extensive demographic, social, clinical, anthropometric, and biochemical data were collected according to predefined criteria. Social class was coded into six categories (registrar general's classification) and mother's education according to categories published previously. ${ }^{16}$

Of the 424 infants enrolled, 377 survived. Of the 47 who died, 19 were in trial A ( $8 / 79$ on term formula and $11 / 81$ on preterm formula) and 28 in trial B (14/132 in each diet group). Appointments were sent to the 366 survivors still resident in the United Kingdom; consent for participation was refused in only six cases. Follow up thus comprised $96 \%$ survivors $(360 / 377)$ and over $98 \%(360 / 366)$ of those still in Britain. We assessed intelligence quotient (IQ) with the Weschler intelligence scale for children (revised anglicised version: WISC-R UK). ${ }^{17}$ Because extensive additional data were collected we used an abbreviated version of the intelligence scale with five subsets: similarities, arithmetic, and vocabulary (verbal scale), and block design and

\section{Table 1 Major constituents (per $100 \mathrm{ml}$ ) of trial milks}

\begin{tabular}{|c|c|c|}
\hline Constituent & Preterm formula & Term formula \\
\hline Protein (g) & 2.0 & 1.5 \\
\hline Fat $(\mathrm{g})$ : & 4.9 & 3.8 \\
\hline Saturated (\%) & 39.5 & 39.5 \\
\hline Unsaturated $(\%)$ & 60.5 & 60.5 \\
\hline Carbohydrate (disaccharide, g): & 7.0 & 7.0 \\
\hline Lactose $(\mathrm{g})$ & 6.0 & 7.0 \\
\hline Maltodextrin $(\mathrm{g})$ & 1.0 & - \\
\hline Energy (MJ) & 0.334 & 0.284 \\
\hline Sodium (mg) & 45 & 19 \\
\hline Potassium (mg) & 65 & 57 \\
\hline Chloride (mg) & 60 & 45 \\
\hline Calcium (mg) & 70 & 35 \\
\hline Magnesium (mg) & 5 & 5.2 \\
\hline Phosphorus (mg) & 35 & 29 \\
\hline Iron $(\mu \mathrm{g})$ & 40 & 650 \\
\hline Copper $(\mu \mathrm{g})$ & 120 & 43 \\
\hline Manganese $(\mu \mathrm{g})$ & 3 & 3.4 \\
\hline Zinc $(\mu \mathrm{g})$ & 1000 & 350 \\
\hline lodine $(\mu \mathrm{g})$ & 7 & 4.5 \\
\hline Vitamin A $(\mu \mathrm{g})$ & 100 & 100 \\
\hline Vitamin D $(\mu \mathrm{g})$ & 8.0 & 1.0 \\
\hline Vitamin $\mathrm{E}(\mu \mathrm{g})$ & 10 & 0.48 \\
\hline Vitamin K $(\mu \mathrm{g})$ & 7 & 2.7 \\
\hline Vitamin B-1 $(\mu \mathrm{g})$ & 95 & 42 \\
\hline Vitamin B-2 $(\mu \mathrm{g})$ & 180 & 55 \\
\hline Niacin/niacinamide $(\mu \mathrm{g})$ & 1000 & 690 \\
\hline Vitamin B-6 $(\mu \mathrm{g})$ & 100 & 35 \\
\hline Vitamin B-12 $(\mu \mathrm{g})$ & 0.2 & 0.14 \\
\hline Folic acid $(\mu \mathrm{g})$ & 50 & 3.4 \\
\hline Pantothenic acid $(\mu \mathrm{g})$ & 500 & 230 \\
\hline Biotin $(\mu \mathrm{g})$ & 2.0 & 1.0 \\
\hline Vitamin C $(\mu \mathrm{g})$ & 28 & 6.9 \\
\hline Choline (mg) & 5.6 & $5^{*}$ \\
\hline Inositol (mg) & 3.2 & $5^{*}$ \\
\hline Taurine (mg) & 5.1 & Trace \\
\hline Carnitine (mg) & 1.0 & $2^{*}$ \\
\hline Casein (whey ratio) & $40: 60$ & $40: 60$ \\
\hline
\end{tabular}

*Values not measured for every batch. Approximate figures are given. 
Table 2 Characteristics of subjects followed up at $71 / 2$ to 8 years and early physical growth according to diet of standard term formula or preterm formula

\begin{tabular}{|c|c|c|c|c|c|c|}
\hline \multirow[b]{2}{*}{ Characteristic } & \multicolumn{2}{|c|}{ Trial A (as sole diets) } & \multicolumn{2}{|c|}{$\begin{array}{c}\text { Trial B (as supplements to } \\
\text { mother's milk) }\end{array}$} & \multicolumn{2}{|c|}{$\begin{array}{c}\text { Trial A+B (as sole diets or } \\
\text { supplements) }\end{array}$} \\
\hline & $\begin{array}{l}\text { Standard } \\
\text { formula }\end{array}$ & $\begin{array}{l}\text { Preterm } \\
\text { formula }\end{array}$ & $\begin{array}{l}\text { Standard } \\
\text { formua }\end{array}$ & $\begin{array}{l}\text { Preterm } \\
\text { formula }\end{array}$ & $\begin{array}{l}\text { Standard } \\
\text { formula }\end{array}$ & $\begin{array}{l}\text { Preterm } \\
\text { formula }\end{array}$ \\
\hline No of children followed up & 68 & 67 & 113 & 112 & 181 & 179 \\
\hline No of children developmentally assessed & 67 & 66 & 112 & 110 & 179 & 176 \\
\hline No of boys & 35 & 24 & 50 & 59 & 85 & 83 \\
\hline No small for gestation (<10th centile) & 23 & 24 & 45 & 42 & 68 & 66 \\
\hline Mean (SE) birth weight $(\mathrm{g})$ & $1354(66)$ & $1404(38)$ & $1425(28)$ & $1424(29)$ & $1399(22)$ & $1416(23)$ \\
\hline Mean (SE) gestation (weeks) & $30.6(0.3)$ & $30.9(0.3)$ & $31.2(0.2)$ & $31.3(0.3)$ & $31.0(0.2)$ & $31.2(0.2)$ \\
\hline No needing mechanical ventilation for $\geqslant 14$ days & 6 & 6 & 9 & 13 & 15 & 19 \\
\hline Mean (SE) time to attain full enteral feeds (days) & $13.1(1.4)$ & $13.4(1.3)$ & $12.4(1.0)$ & $12.2(1.1)$ & $12.7(0.8)$ & $12.7(0.8)$ \\
\hline No with parents of non-manual social class & 11 & 14 & 43 & 46 & 54 & 60 \\
\hline No of mothers with higher education & 4 & 1 & 27 & 30 & 31 & 31 \\
\hline Mean (SE) steady state weight gain while on diet ( $\mathrm{g} / \mathrm{kg} /$ day) & $20.3(0.9)$ & $29.8(1.0)^{\star \star \star *}$ & $22.4(0.6)$ & $25.2(0.7)^{\star *}$ & $21.6(0.5)$ & $25.8(0.6)^{\star * \star}$ \\
\hline Mean (SE) head circumference gain while on diet (mm/day) & $1.2(0.08)$ & $1.5(0.08)^{\star \star}$ & $1.4(0.06)$ & $1.4(0.05)$ & $1.3(0.05)$ & $1.4(0.04)$ \\
\hline Median days in study (25th, 75 th centiles) & $33(21,49)$ & $26(18,42)$ & $30(19,52)$ & $28(19,45)$ & $30(20,50)$ & $28(19,45)$ \\
\hline
\end{tabular}

${ }^{\star *} \mathrm{P}<0.005,{ }^{* *}{ }^{*} \mathrm{P}<0.001$ by $t$ test.

object assembly (performance scale). The abbreviated revision assessed from these five subscales has a correlation coefficient with the full revised scale of over $0.96{ }^{18}$ Of children followed up, 24 had cerebral palsy (with neurological signs and motor impairment), and four of these and a blind child were too disabled for full IQ testing; thus full assessments were made on $99 \%$ $(355 / 360)$ of those seen (of the five children not tested, three were fed preterm formula and two were fed standard formula).

\section{Analysis}

Data were analysed as randomised in accordance with the trial protocol and standard practice. Statistical analyses included Student's $t$ test, $\chi^{2}$ test, Fisher's exact test, and multiple regression. Data from children with cerebral palsy who could be tested were included in these tests but excluded from further analyses. A sample size of 288 subjects was calculated at the outset to detect a $0.33 \mathrm{SD}$ difference (5 points) in overall IQ between feed groups (A and B combined) at the 5\% significance level with over $80 \%$ power. (In fact, the follow up of 360 subjects permitted a 4.5 point difference to be detected.) For trial A alone a sample size of 128 subjects was calculated to detect a $0.5 \mathrm{SD}$ difference (7.5 points) in overall IQ (recruitment achieved was slightly higher than this at 133 subjects). On the basis of our previous follow up of this cohort, these hypothesised differences were plausible. ${ }^{12}$

\section{Results}

Table 2 shows characteristics of the study population. The randomised groups did not differ significantly in demographic or clinical characteristics. Those fed preterm formula had greater neonatal weight gain in trials $\mathrm{A}$ and $\mathrm{B}$ and greater gain in head circumference in trial A. Period spent on the trial diets was similar in both randomised feed groups (median 4 weeks). Detailed analyses showed no differences between groups in trials A, B, or A plus B in total intravenous volume, energy, protein, or lipid.

The incidence of intraventricular haemorrhage did not differ between groups. Larger babies were not rou- tinely scanned, and ultrasound data were available for $59 \%$ of cases. For trials A plus B 30/126 (24\%) babies had documented intraventricular haemorrhage in the standard formula group and $27 / 124(22 \%)$ in the preterm formula group; for more severe, grade 3 or 4 intraventricular haemorrhage, respective numbers were $11(8.7 \%)$ versus $10(8.1 \%)$. For trial A alone total numbers of babies with intraventricular haemorrhage for the standard versus preterm formula groups were $14 / 49(29 \%)$ versus 16/48 (33\%); and six in each group had grade 3 or 4 haemorrhage.

\section{Measurements of IQ}

Table 3 shows performance, verbal, and overall IQ scores at $7 \frac{1 / 2}{2}$ to 8 years. In trial A verbal IQ was 4.8 points lower $(\mathrm{P}=0.8)$ in those fed solely a standard term formula rather than preterm formula. The differences in IQ seen between groups in trial A or B or in trial A plus B combined were not significant $(\mathrm{p}>0.05)$. (The higher IQ of children in trial $\mathrm{B}$, who were fed their own mother's milk, compared with IQ of those in trial A has been reported previously. ${ }^{19}$ )

Some infants received little trial diet either because of early discharge or prolonged intravenous feeding. In trial B consumption of trial formula was low when mothers provided sufficient breast milk. In explanatory analyses we tested whether differences between feed groups were blunted by low intake of the trial diets. Analyses confined to 218 selected infants in trial A or B who received at least 2 weeks of full enteral feeds and to those from trial B who had received over $50 \%$ (mean $80 \%$ ) of total enteral intake of trial formula generally showed accentuation of the difference between diet groups (table 4). There was a 4.6 point advantage $(\mathrm{P}=0.053)$ in verbal IQ and a 3.7 point advantage in overall IQ $(\mathrm{P}=0.08)$ for those fed preterm rather than term formula.

In view of our previous finding in this cohort at 18 months of age of a significant interaction between diet and sex in relation to developmental scores $^{12}$ we analysed data here by sex. Table 5 shows dietary effects on verbal and overall IQ. The beneficial effect of preterm formula on verbal IQ was seen for boys but not girls and was confined to those fed exclusively on 
Table 3 Intelligence quotients (IQs) measured by Weschler revised intelligence scale for children ${ }^{\star}$ (verbal, performance, and overall IQ) at $71 / 2$ to 8 years according to diet. Standard term formula and preterm formula compared as sole diets (trial A), as supplements to mother's milk (trial $B$ ), and in trials $A$ and $B$ combined. Values are group means (SE)

\begin{tabular}{lccc} 
& \multicolumn{2}{c}{ Milk formula } & Advantage for preterm \\
Detail & Standard & Preterm & \\
\cline { 2 - 3 } formula $\mathbf{9 5 \%}$ CI)
\end{tabular}

${ }^{*}$ Abbreviated form; see text.

†Numbers vary by up to two subjects in individual cells; see text.

Table 4 Intelligence quotients (IQS) measured by Weschler revised intelligence scale for children* (verbal, performance, and overall IQ) at $7 \frac{1}{2}$ to 8 years according to diet for infants who received highest intakes of trial diet. Standard term formula and preterm formula compared as sole diets (trial A), as supplements to mother's milk (trial $B$ ), and in trials $A$ and $B$ combined. Values are group means (SE)

\begin{tabular}{|c|c|c|c|}
\hline \multirow[b]{2}{*}{ Detail } & \multicolumn{2}{|c|}{ Milk formula } & \multirow{2}{*}{$\begin{array}{l}\text { Advantage for preterm } \\
\text { formula }(95 \% \mathrm{CI})\end{array}$} \\
\hline & Term & Preterm & \\
\hline \multicolumn{4}{|l|}{ Trial A } \\
\hline No of subjects $†$ & 56 & 56 & \\
\hline Verbal IQ & $93.3(2.3)$ & $98.2(1.9)$ & $4.9(-0.9$ to 10.7$)$ \\
\hline Performance IQ & $96.3(2.0)$ & $96.6(2.3)$ & $0.3(-5.8$ to 6.3$)$ \\
\hline Overall IQ & $94.6(1.9)$ & $97.6(1.9)$ & $3.0(-2.3$ to 8.3$)$ \\
\hline \multicolumn{4}{|l|}{ Trial B } \\
\hline No of subjects $†$ & 55 & 51 & \\
\hline Verbal IQ & $96.3(2.5)$ & $100.7(2.9)$ & $4.4(-3.1$ to 12.0$)$ \\
\hline Performance IQ & $100.5(2.3)$ & $103.4(2.3)$ & $2.9(-3.6$ to 9.5$)$ \\
\hline Overall IQ & $97.7(2.2)$ & $102.5(2.3)$ & $4.6(-1.8$ to 11.0$)$ \\
\hline \multicolumn{4}{|l|}{ Trial $A$ and $B$} \\
\hline No of subjects† & 111 & 107 & \\
\hline Verbal IQ & $94.8(1.7)$ & $99.4(1.7)$ & $4.6(-0.07$ to 9.3$) \ddagger$ \\
\hline Performance IQ & $98.4(1.5)$ & $99.8(1.7)$ & $1.4(-3.1$ to 5.9$)$ \\
\hline Overall IQ & $96.2(1.5)$ & $99.9(1.5)$ & 3.7 (-0.5 to 7.8$)$ \\
\hline
\end{tabular}

*Abbreviated form; see text.

†Numbers vary by up to two subjects in individual cells; see text. $\ddagger \mathrm{P}=0.053$ by $t$ test.

the trial diets (trial A). Boys on the preterm formula had a $12.2(95 \%$ confidence interval 3.7 to 20.6$)$ point advantage in verbal IQ and a 6.3 ( -1.5 to 14.2$)$ point advantage in overall IQ, whereas no effect was seen in girls (test for interaction $\mathrm{P}=0.009$ and 0.09 , respectively).

Advantages in verbal and overall IQ were even larger among boys who received the highest intake of trial diet. The advantage in verbal IQ was 14.4 (5.7 to 23.2) and in overall IQ was 9.5 (1.2 to 17.7) points for boys with the highest intakes of preterm formula. No effect was seen in girls (test for interaction $\mathrm{P}=0.002$ and 0.02 , respectively).

Children with cerebral palsy and low IQ scores The analyses above included children with cerebral palsy whose IQ was measured. In trial A, however, cerebral palsy was significantly more common among those fed standard rather than preterm formula $(8 / 67$ v $1 / 66 ; \mathrm{P}=0.03$ by Fisher's exact test). To explore whether this imbalance could explain the disadvantageous outcome of those fed the standard formula, further analyses were performed with exclusion of data from those children with cerebral palsy. The disadvantage for the standard formula remained-for example, verbal IQ in boys fed standard versus preterm formula was 9.7 points lower (95\% confidence interval 1.1 to $18.3 ; \mathrm{P}=0.03)$.

Significantly more children fed standard versus preterm formula had low verbal IQ $(<85)$. Table 6 shows this analysis both including and excluding subjects with cerebral palsy. In children previously fed standard formula the proportion with low verbal IQ was over twice that in the group fed with preterm formula; in boys the difference was over threefold. Not all children with cerebral palsy had low IQ. To derive an overall category of children with poor outcome we calculated the proportion of children with either low verbal IQ scores $(<85)$ or cerebral palsy as these outcomes were separately affected by diet. Table 6 shows the greater proportion of infants in this category from trial A had been fed term rather than preterm formula (38\% $v 15 \% ; \mathrm{P}=0.003)$ - a difference most pronounced in boys $(54 \%$ v $17 \% ; \mathrm{P}=0.004)$. In corresponding analyses for trials A plus $B(n=360$; not tabulated) boys and girls were again more likely to be in the category with poor outcome if they had received the standard versus preterm formula $(25 \%(45 / 181$, including 16 children with cerebral palsy) versus $16 \%$ (29/179, including eight children with cerebral palsy); $\mathrm{P}=0.05)$; the effect was greatest in boys $(33 \%(28 / 85)$ versus $18 \%(15 / 83) ; \mathrm{P}=0.027)$.

\section{Discussion}

In this prospective, blinded, randomised outcome trial, with follow up of $98 \%$ of survivors still in Britain, the diet assigned to a premature baby for an average of just 4 weeks after birth had a significant effect on IQ-notably verbal IQ in boys-71/2-8 years later when IQ scores are highly predictive of subsequent ones. ${ }^{14}$ Our findings suggest that suboptimal early nutrition in preterm infants can have a permanent effect on their cognitive function, emphasising the potential importance of dietary management decisions in this population. In biological terms our findings now provide "experimental" evidence in humans to support the long debated hypothesis that nutrition during critical or vulnerable periods of brain growth may have lasting consequences for cognition. ${ }^{5} 10$

Apart from its broader biological purpose, this study examined the practical question of whether early diet influences outcome in a typical, unselected, and heterogeneous preterm population in a neonatal unit. We did not study whether the perinatal sensitivity to nutrition identified extended beyond full term. While many other investigators have approached this ${ }^{1-6}$ there 
is still a paucity of formal randomised studies. ${ }^{8}$ The only strictly randomised study of post-term nutrition on long term outcome is that by Grantham-McGregor et al on 127 subjects. They showed a small increase in cognitive function at follow up in nutritionally supplemented stunted children in a developing country. ${ }^{20}$

Our data also show (tables 2 and 3) the higher IQ in children whose early diet included their own mother's milk (trial B) versus those fed solely on formula (trial A). This non-randomised comparison has been published elsewhere ${ }^{19}$ and does not confound the present study, which considers the randomised comparison of standard infant formula versus nutrient enriched preterm formula used either as sole diets (trial A), as supplements to mother's milk (trial B), or in the balanced addition of trials $\mathrm{A}$ and $\mathrm{B}$ which preserves randomisation.

\section{Sex differences in the effect of diet}

Previously and in another cohort (comparing preterm formula with banked donor breast milk) we found that effects on development induced by early diet were most prominent for language development. ${ }^{21}$ Again at 71/2-8 years verbal or language based skills were predominantly affected. Lack of dietary effect on performance skills, however, might reflect our choice of only two performance subscales (block design and object assembly) in this abbreviated form of the Weschler intelligence scale for children (revised). This issue will be resolved at future planned follow up.

In animal studies long term consequences of early malnutrition on learning and behaviour are seen predominantly in males. ${ }^{22}$ Also, in the study by
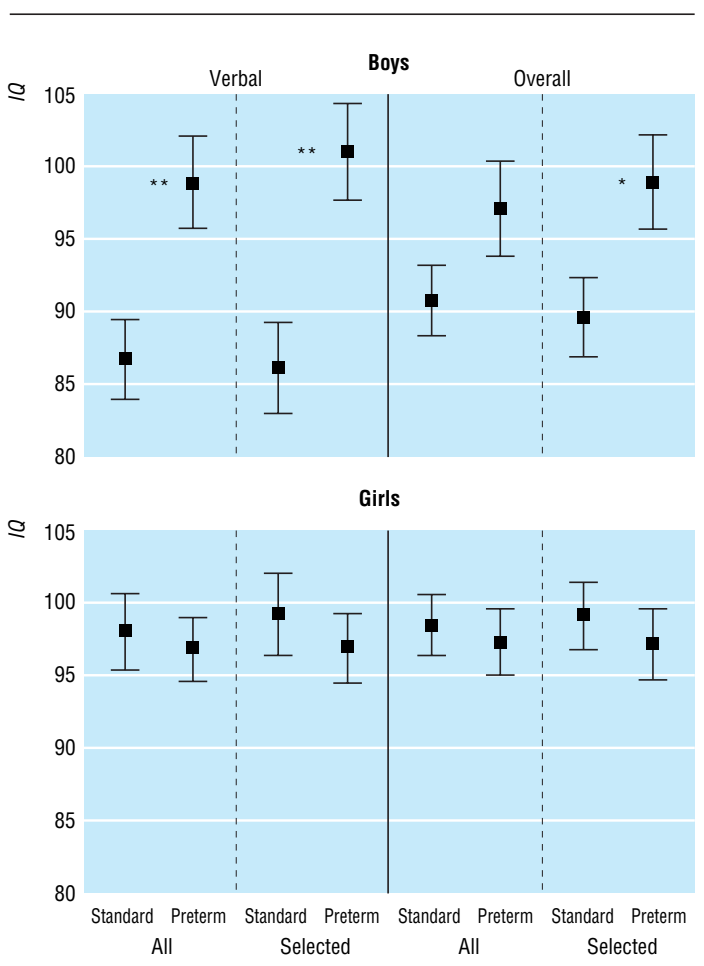

Fig 2 Mean (SE) verbal intelligence quotient (IQ) and overall IQ in boys and girls fed standard versus preterm formula as their sole diet. Dietary comparison is made for all boys and also for those receiving highest intakes of trial diets (see text). ${ }^{*}<0.05$; ${ }^{\star *} P<0.01$
Table 5 Influence of sex on beneficial effects (95\% confidence intervals) of preterm formula milk on verbal and overall IQ

\begin{tabular}{|c|c|c|c|c|}
\hline \multirow{2}{*}{$\begin{array}{l}\text { Trial } \\
\text { (sex) }\end{array}$} & \multicolumn{2}{|c|}{ Gain in verbal IQ } & \multicolumn{2}{|c|}{ Gain in overall IQ } \\
\hline & All & Selected† & All & Selected† \\
\hline \multicolumn{5}{|c|}{ Trial A } \\
\hline Boys & $12.2^{* *}$ (3.7 to 20.6) & $14.4^{* *}$ (5.7 to 23.2) & $6.3(-1.5$ to 14.2$)$ & $9.5^{\star}(1.2$ to 17.7$)$ \\
\hline Girls & $-2.2(-9.0$ to 4.6$)$ & $-3.4(-10.7$ to 3.9$)$ & $-2.2(-8.4$ to 4.1$)$ & $-2.8(-9.5$ to 3.9$)$ \\
\hline \multicolumn{5}{|c|}{ Trial B } \\
\hline Boys & $-3.7(-10.6$ to 3.2$)$ & $-0.7(-10.5$ to 12.0$)$ & $-1.0(-6.4$ to 4.4$)$ & $2.7(-6.1$ to 11.5$)$ \\
\hline Girls & $4.4(-2.4$ to 11.3$)$ & 7.7 (-2.8 to 18.2$)$ & 3.0 (-3.1 to 9.1) & $6.3(-3.1$ to 15.7$)$ \\
\hline \multicolumn{5}{|c|}{ Trial $A+B$} \\
\hline Boys & $2.9(-2.7$ to 8.4$)$ & $7.9^{*}(0.8$ to 15.0$)$ & 2.6 (-2.0 to 7.2$)$ & $6.5^{*}$ (0.5 to 12.5$)$ \\
\hline Girls & 1.2 (-3.8 to 6.2$)$ & 1.8 (-4.4 to 8.1$)$ & 0.3 (-4.1 to 4.8$)$ & $1.3(-4.3$ to 6.9$)$ \\
\hline
\end{tabular}

${ }^{*} \mathrm{P}<0.05,{ }^{*} \mathrm{P}<0.01$ by $t$ test.

†Infants who received highest intakes of trial diet (see text).

Table 6 Proportions (percentages) of children with low verbal $I Q\left(<85^{\star}\right)$, cerebral palsy, or combination (low verbal IQ or cerebral palsy) according to diet in trial A† (standard term formula and preterm formula compared as sole diets)

\begin{tabular}{|c|c|c|c|c|}
\hline \multirow[b]{2}{*}{ Detail } & \multicolumn{2}{|c|}{ Milk formula } & \multirow{2}{*}{$\begin{array}{l}\text { Odds ratio } \\
\text { (95\% Cl) }\end{array}$} & \multirow{2}{*}{$\begin{array}{c}P \text { value by Fisher's } \\
\text { exact test }\end{array}$} \\
\hline & Term & Preterm & & \\
\hline \multicolumn{5}{|c|}{ No (\%) with verbal IQ <85‡: } \\
\hline All & $21 / 67(31)$ & $9 / 66(14)$ & $2.9(1.2$ to 6.9$)$ & 0.022 \\
\hline Boys & $16 / 34(47)$ & $3 / 24(13)$ & $6.2(1.6$ to 24.8$)$ & 0.009 \\
\hline Girls & $5 / 33(15)$ & $6 / 42(14)$ & $1.1(0.2$ to 3.9$)$ & 1.0 \\
\hline \multicolumn{5}{|c|}{ No (\%) with verbal IQ <85 excluding children with cerebral palsył: } \\
\hline All & $18 / 60(30)$ & $9 / 65(14)$ & 2.7 (1.1 to 6.5$)$ & 0.03 \\
\hline Boys & $13 / 29(45)$ & $3 / 23(13)$ & $5.4(1.3$ to 22.3$)$ & 0.02 \\
\hline Girls & $5 / 31(16)$ & $6 / 42(14)$ & $1.2(0.3$ to 4.2$)$ & 1.0 \\
\hline \multicolumn{5}{|c|}{ No (\%) with cerebral palsy: } \\
\hline All & $8 / 68(12)$ & $1 / 67(1.5)$ & $8.8(1.1$ to 72.4$)$ & 0.03 \\
\hline Boys & $6 / 35(17)$ & $1 / 24(4.2)$ & $4.7(0.5$ to 41.5$)$ & 0.13 \\
\hline Girls & $2 / 33(6.1)$ & $0 / 43$ & & 0.19 \\
\hline \multicolumn{5}{|c|}{ No (\%) with cerebral palsy or verbal IQ <85‡: } \\
\hline All & $26 / 68(38)$ & $10 / 66(15)$ & $3.4(1.5$ to 8.0$)$ & 0.003 \\
\hline Boys & $19 / 35(54)$ & $4 / 24(17)$ & $5.9(1.7$ to 21.0$)$ & 0.004 \\
\hline Girls & $7 / 33(21)$ & $6 / 42(14)$ & $1.6(0.5$ to 5.4$)$ & 0.54 \\
\hline
\end{tabular}

*Weschler abbreviated scale, revised, see text.

†See text for data on trials $A$ and $B$ combined.

fOne child who did not have cerebral palsy could not be psychometrically assessed.

Fitzhardinge and Steven on full term infants who are small for gestational age only boys had later cognitive deficits. ${ }^{23}$ Our analysis according to sex was the principal preplanned subgroup analysis and was further justified by the significant interaction between sex and diet (significantly different impact of diet on development). Interestingly, the observed dietary effects on cognitive scores were significant only in boys. Also, although an effect of diet on the proportion of children with "poor outcome" was seen in both boys and girls, again the dominant effect was in boys. There was no cognitive disadvantage for boys versus girls when a nutrient enriched preterm formula was used (fig 2); only when boys were fed suboptimally (on standard formula) was there a major loss of cognitive potential. Why the male brain should be so vulnerable to early nutritional insults is an unresolved biological issue. We found no sex difference in mean gestation or birth weight. Boys, however, as expected, were sicker with $25 \%(42 / 168)$ requiring ventilation for more than 7 days compared with $16 \%(30 / 190)$ in girls. This could in part explain the sex effect if diet had more impact on later cognitive development in sicker individuals; indeed, a previous analysis provided some evidence for this. ${ }^{21}$ 
As the principal effects were seen in boys and in trial A our data may reflect a chance finding in a subpopulation of our cohort. Several factors, however, argue against this. As trial B reflected a comparison of trial diets substantially blunted by use of human milk in both groups it is not surprising that the effects of diet are seen in trial A. Furthermore, when we selected subjects for the highest intakes of the trial formulas (given for at least 2 weeks and, in trial B, at least $50 \%$ of enteral intake as formula) dietary effects were more distinct (for instance, boys selected in this way and fed solely on term rather than preterm formula had a major disadvantage of around 10 points in overall IQ versus 6 points in non-selected boys). This relation between the effect size and amount of trial diets consumed favours a causal relation. We also found an advantage of preterm formula over banked donated breast milk at a 9 month follow up in an entirely different though parallel cohort; this study also showed an effect predominantly in boys, as in the numerous animal and human studies cited above.

\section{Diet and cerebral palsy}

Unexpectedly, among infants fed the standard rather than preterm formula cerebral palsy was significantly more common, and we explored whether the lower cognitive scores seen in those fed standard formula were due to this imbalance. This proved not to be the case; even with specific analysis of data from children with cerebral palsy, low verbal scores $(<85$; over $1 \mathrm{SD}$ below the mean) were seen over twice as commonly in both boys and girls previously fed the term rather than preterm formula and over three times as commonly in boys $(45 \% v 13 \%)$.

The association between diet and cerebral palsy (largely spastic diplegia) was a post hoc finding but raises a clinically important hypothesis for formal testing. There is evidence from newborn rats and preterm monkeys that the brain may reorganise to achieve complete functional compensation if cortical damage occurs sufficiently early. ${ }^{24}$ It is plausible that, although cerebral palsy in prematurely born children might originate prenatally or at least before enteral feeding has commenced, whether the brain can subsequently achieve functional compensation at a time of rapid brain growth and development might depend on the provision of adequate nutrient substrates. Indeed, in the average period on the trial diets (4 weeks) the preterm infant's brain should increase by $50 \%$ in weight at "in utero" rates. ${ }^{25}$ We showed here a major deficit in head $^{12}$ and therefore brain ${ }^{25}$ growth during the neonatal period in those fed the term formula. Further studies are needed, however, to investigate the issues here.

\section{Clinical implications}

The two trial formulas (table 1) differed in their contents of protein, energy, calcium, phosphorus, iron, zinc, copper, and several other micronutrients, though not in quality of protein or fat. Our trial was not designed to explore which nutrients influenced neurodevelopment. Broadly our findings support the generic hypothesis that failure to meet overall nutrient needs during this critical period of brain growth has significant consequences for cognitive development. While standard "term" formulas, widely used when our cohort was recruited, are now infrequently fed to very
- Suboptimal nutrition during sensitive stages in early brain development may have long term effects on cognitive function

- In a randomised trial of early nutrition in preterm infants those fed standard rather than nutrient enriched preterm formula had reduced verbal IQ scores at $71 \frac{12}{2}$ to 8 years, at least in boys

- In exploratory analyses on children of both sexes verbal IQ below 85 and cerebral palsy were more prevalent in the standard formula group

- Our data show the potential vulnerability of the human brain to early suboptimal nutrition

- Avoidance of undernutrition in sick preterm infants seems important in optimising later neurodevelopmental outcomes

low birthweight preterm infants, poor nutritional status remains common in these babies; our findings therefore have contemporary relevance in emphasising the importance of avoiding this.

In conclusion, we have shown that brief early dietary manipulation in preterm infants has major effects on later cognitive function. The study provides further support for our more general thesis ${ }^{26}$ that early nutrition during critical windows in early life may have "programming" effects on long term outcomes and provides some of the first evidence from a strictly randomised, blinded, and long term trial with near complete follow up that early nutrition may have persistent effects on the human brain.

We thank the Medical Research Council for its core support; the staff of the neonatal units in Norwich and Sheffield; Drs C E S Leeson-Payne and G Lister for their major contribution in developmental testing of the subjects; Drs P M Crowle and RJ Pearse for their collaboration; Evelyn Smith for preparing the manuscript; and, in particular, the children taking part in the study, their families, and the schools which provided accommodation.

Contributors: AL initiated and conceived the original study hypothesis and design and participated in analysing the results and writing the paper. RM participated in the core study design, selected the neurodevelopmental outcome tools used, performed the developmental tests, and supervised and trained two other field workers in their use; RM also participated in analysing and checking data and writing the paper. TC gave statistical advice throughout the study, made key contributions to data interpretation and presentation, and discussed the paper with the other authors during its production. AL is the guarantor of the study.

Funding: Contribution from Farley Health Products (a division of $\mathrm{HJ}$ Heinz). The preterm formula was designed by us for this study and manufactured and supplied by Farleys.

Competing interests: None declared.

1 Gardner JM, Grantham-McGregor SM. Physical activity, undernutrition and child development (review). Proc Nutr Soc 1994;53:241-8.

2 Pollitt E, Gorman KS, Engle PL, Martorell R, Rivera J. Early supplementary feeding and cognition: effects over two decades. Monogr Soc Res Child Dev 1993;58.

3 Grantham-McGregor SM, Powell CA, Walker SP, Himes JH. Nutritional supplementation, psychosocial stimulation and mental development of stunted children: the Jamaican study. Lancet 1991;338:1-5.

4 Husaini MA, Karyadi L, Husaini YK, Sandjaja B, Karyadi D, Pollitt E. Developmental effects of short-term supplementary feeding in nutritionally at-risk Indonesian infants. Am J Clin Nutr 1991:54:799-804.

5 Dobbing J. Nutritional growth restriction and the nervous system. In: Davison AN, Thompson RHS, eds. The molecular basis of neuropathology. London: Edward Arnold, 1981:221-3. 
6 Grantham-McGregor S. Field studies in early nutrition and later achievement. In: Dobbing J, ed. Early nutrition and later achievement. London: Academic Press, 1987:128-74.

7 Richardson SA. The relation of severe malnutrition in infancy to the intelligence of school children with differing life histories. Pediatr Res 1976;10:57-61.

8 Smart JL. Malnutrition, learning and behavior: 25 years on from the MIT symposium. Proc Nutr Soc 1993;52:189-99.

Katz HG. The influence of undernutrition on learning performance in rodents. Nutr Abs Rev 1980;50:767-83.

10 Smart JL. Early life malnutrition and later learning ability-critical analysis. In: Oliverio A, ed. Genetics, environment and intelligence. Amsterdam: Elsevier, 1977:215-35.

11 Lucas A, Gore SM, Cole TJ, Bamford MF, Dossetor JF, Barr I, et al. Multicentre trial on feeding low birthweight infants: effects of diet on early growth. Arch Dis Child 1984;59:722-30.

12 Lucas A, Morley R, Cole TJ, Gore SM, Lucas PJ, Crowle P, et al. Early diet in preterm babies and developmental status at 18 months. Lance 1990;335:1477-81.

13 Lucas A. Enteral nutrition. In: Tsang R, Lucas A, Uauy R, Zlotkin S, eds. Nutritional needs of the preterm infant. Pawling, United States: Caduceus Medical Publishers, 1993:209-23.

14 McCall RB. The development of intellectual functioning in infancy and the prediction of later IQ. In: Osofsky JD ed. The handbook of infant development. New York: Wiley, 1979:707-41.

15 Cronbach LJ. Essentials of psychological testing. New York: Harper Collins, 1990:284.

16 Morley R, Cole TJ, Powell R, Lucas A. Mother's choice to provide breast milk and developmental outcome. Arch Dis Child 1988;63:1382-5.
17 Psychological Corporation. Wechsler intelligence scale for children, Anglicised. Rev ed. Sidcup: Psychological Corporation, 1974.

18 McNemar Q. Correction to a correction. J Consult Clin Psychol 1974;42:145-6.

19 Lucas A, Morley R, Cole TJ, Lister G, Leeson-Payne C. Breast milk and subsequent intelligence quotient in children born preterm. Lancet 1992:339:261-4.

20 Grantham-McGregor SM, Walker SP, Chang SM, Powell CA. Effects of early childhood supplementation with and without stimulation on later development in stunted Jamaican children. Am J Clin Nutr 1997;66:247 53.

21 Lucas A, Morley R, Cole TJ, Bamford MF, Boon A, Crowle P, et al. Early diet in preterm babies and developmental status in infancy. Arch Dis Child 1989;11:1570-8.

22 Smart JL. Undernutrition, learning and memory: review of experimental studies. In: Taylor TG, Jenkins NK, eds. Proceedings of XIII international congress of nutrition. London: John Libbey, 1986:74-8.

23 Fitzhardinge PM, Steven EM. The small-for-date infant. II. Neurologica and intellectual sequelae. Pediatrics 1972;50:50-7.

24 Kolb B, Whishaw IQ. Development and recovery. In: Fundamentals of neuropsychology. 3rd ed. New York: Freeman, 1990:679-711.

25 Cooke RWI, Lucas A, Yudkin PLN, Pryse-Davies J. Head circumference as an index of brain weight in the fetus and newborn. Early Hum Der 1977;1/2:145-9

26 Lucas A. Programming by early nutrition in man. In: Barker D, ed. The childhood environment and adult disease. Chichester: Wiley, 1991:38-55. (CIBA Foundation Symposium 156.)

(Accepted 27 August 1998)

\title{
Randomised controlled trial of novel, simple, and well supervised weight reducing diets in outpatients
}

\author{
Carolyn D Summerbell, Carolyn Watts, Julian P T Higgins, John S Garrow
}

\begin{abstract}
Objectives To investigate the contribution of novelty and simplicity to compliance with a low energy diet among obese outpatients.

Design Three arm randomised trial for 16 weeks. Setting NHS hospital obesity clinic.

Subjects 45 patients aged over 17 years with a body mass index $>27$ who were not diabetic, pregnant, or lactating.

Interventions Conventional 3.4 MJ diet (control), isoenergetic novel diet of milk only, or milk plus one designated food daily. Follow up visit every 4 weeks.

Main outcome measure Weight loss.

Results Mean weight loss (kg) after 16 weeks on control, milk only, and milk plus diets was 1.7 (95\% confidence interval -0.3 to 3.7$), 9.4$ (5.9 to 12.9 ), and 7.0 (2.7 to 11.3 ) respectively. Weight loss on the novel diets was significantly greater than on the control diet. Conclusions Dietary treatment can achieve as much weight loss in obese outpatients over 16 weeks as has been reported for the most successful drug treatment, but compliance with the prescribed diet is poor unless the diet is novel and simple.
\end{abstract}

\section{Introduction}

Outpatient dietary weight reduction for obesity is unsatisfactory, ${ }^{12}$ but inpatient dieting is extremely effective. ${ }^{3}$ Obese patients lose weight more rapidly as inpatients than as outpatients when nominally on the same diet, which can be explained only by compliance. ${ }^{4}$ Some of the most impressive weight losses achieved by outpatient dietary treatment have been in the placebo control arm of drug trials. ${ }^{56}$ The ambience of a controlled drug trial seems to be conducive to high compliance with dietary treatment and hence good weight loss. The patient is reviewed regularly and believes that the treatment is something novel which may succeed.

This study was designed to test the hypothesis that prescription of simple, novel diets would result in higher levels of compliance and weight loss in an outpatient setting over 16 weeks. Patients were randomised to one of three diets, each of which was designed to produce an initial energy deficit of 4-7 MJ a day.

\section{Subjects and methods}

\section{Recruitment and randomisation}

All new patients aged over 17 attending an obesity outpatient clinic at St Bartholomew's Hospital between 1 November 1993 and 13 May 1994 were eligible if their body mass index (weight $(\mathrm{kg}) /\left(\right.$ height $\left.(\mathrm{m})^{2}\right)$ was $>27$ and they were not diabetic, pregnant, or lactating. Eligibility was assessed by JSG, who was blind to the subsequent allocation of treatment.

All patients had their weight and height measured by the clinic nurse and were given appointments to return to the clinic every four weeks for 16 weeks. At the first visit JSG took a medical history and did a physical examination. CDS then performed the initial randomisation, gave dietary advice, and explained how to record dietary intake. Randomisation was achieved by using blocks of six sealed, opaque envelopes (equal allocation) from which sequential patients chose one. Exact blocking was disturbed because a partly used block of envelopes was mislaid. At subsequent visits

\author{
Rank Department \\ of Human \\ Nutrition, \\ St Bartholomew's \\ Hospital Medical \\ College, London \\ EC1M 6BQ \\ Carolyn D \\ Summerbell, \\ lecturer in nutrition \\ Carolyn Watts, \\ research dietitian \\ John S Garrow, \\ professor of human \\ nutrition \\ Department of \\ Epidemiology and \\ Public Health, \\ Institute of Child \\ Health, London \\ WC1N 1EH \\ Julian P T Higgins, \\ research fellow in \\ medical statistics \\ Correspondence to: \\ Dr Summerbell, \\ School of Health, \\ University of \\ Teesside, \\ Middlesbrough \\ TS1 3BA \\ carolyn.summerbell@ \\ tees.ac.uk
}

BMJ 1998;317:1487-9 